\title{
EVOLUCIÓN DE INTERACCIONES PARÁSITO - HOSPEDERO: COEVOLUCIÓN, SELECCIÓN SEXUAL Y OTRAS TEORÍAS PROPUESTAS
}

\section{THE EVOLUTION OF HOST-PARASITE INTERACTIONS: COEVOLUTION, SEXUAL SELECTION AND OTHER SUGGESTED THEORIES}

\begin{abstract}
Guillermo Rico-Hernández
1 MV, M.Sc., Consultor, Instituto de Investigación de Recursos Biológicos "Alexander von Humboldt", Bogotá, D.C., Colombia. gricoh@hotmail.com
\end{abstract}

Rev. U.D.C.A Act. \& Div. Cient. 14(2): 119 - 130, 2011

\section{RESUMEN}

Esta revisión resume los modelos teóricos de interacciones parásito-hospedero que se encuentran disponibles en la literatura científica. Se revisaron publicaciones internacionales en revistas especializadas sobre parasitología y ecología. Estudios teóricos y prácticos de las interacciones parásitohospedero, en algunos casos, sugieren variaciones evolutivas y ecológicas. La evolución de las interacciones parásitohospedero no se limita a consideraciones coevolutivas, sino que tiene efectos directos sobre caracteres de historia de vida del hospedero, evolución del sexo, comportamiento reproductivo, selección sexual e, incluso, sobre transferencia génica. El estudio de las interacciones parásito-hospedero, como fuerzas modeladoras de la evolución y ecología de los organismos, tiene gran importancia, pues aunque, actualmente, carece de evidencia firme en la práctica en algunas de sus áreas y permanece como difícil de demostrar, es clara de manera teórica.

Palabras clave: Parasitismo, modelos teóricos, selección sexual, teoría evolutiva

\section{SUMMARY}

This review summarizes the theoretical models of the parasitehost interactions, available in literature. Articles publishes in international journal specialized in parasitology and ecology were revised. Some theoretical and experimental studies on host-parasite interactions suggest evolutive and ecologic variations. The evolution of host-parasite interactions is not constrained to coevolutive considerations, it has direct effects on host life-history traits, sex evolution, reproductive behavior, sexual selection and even on gene exchange. Even though there is scarcity of evidence in the practice, the study of host-parasite interactions as modelling forces of the evolution and ecology of organisms is a milestone, it is clear in theory.

Key words: Parasitism, theoretical models, sexual selection, evolutive theory

\section{INTRODUCCIÓN}

En la literatura científica es frecuente la publicación de artículos y de libros sobre parasitismo asociados, principalmente, a su manejo farmacológico y a la fisiopatología de los mismos; pero es escasa la generación de conocimiento en aspectos ecológicos y evolutivos del parasitismo. Este tipo de investigaciones, así sea desde ámbitos teóricos, pueden aportar significativamente al conocimiento del papel que ejercen los parásitos sobre los seres vivos.

Se incluye, dentro de este artículo de revisión, evidencias que soportan y controvierten las diferentes teorías que han surgido para explicar las diversas interacciones ecológicas y evolutivas entre parásito y hospedero.

El parasitismo es una forma de interacción ecológica, en la cual, un miembro, el parásito, se beneficia por el uso de recursos reunidos por otro miembro, el hospedero. A través de su historia evolutiva, las especies han convivido con 
poblaciones de parásitos que han regulado, junto con otras interacciones ecológicas, tanto sus tamaños y sus estructuras poblacionales como su estructura genética (O'Brien $\varepsilon$ Evermann, 1988; Dobson \& Hudson, 1992; Barlow, 1996). Los parásitos tienen una influencia sobre los hospederos, similar a la que cumplen los depredadores, los competidores y otros enemigos naturales (Lyles E Dobson, 1993; Boots E Sasaki, 2001). De hecho, la influencia de un parásito en un hospedero puede afectar su respuesta a competidores y mutualistas, su reacción a las condiciones físicas del medio ambiente, su estado de salud, su capacidad reproductiva, su habilidad para obtener recursos o su conservación (Begon et al. 1986; Proctor E Owens, 2000; Cunningham et al. 2003; Daszak et al. 2003; Rico-Hernández, 2004; Rico-Hernández et al. 2004; Stoner et al. 2005; Santos-Angonesi et al. 2009; Valdespino et al. 2010). Es así como la esencia del parasitismo descansa en la interacción parásito-hospedero (IPH).

Una de las áreas de interés en la biología evolutiva es el estudio del proceso mediante, el cual, las interacciones inter-específicas han influido en las tasas de evolución y los patrones de radiación adaptativa de los organismos involucrados. Éste es uno de los aspectos más complejos, pues requiere, en gran manera, la síntesis de dos teorías incompletas: la teoría genética de la evolución y la teoría ecológica de estructura de comunidades (Futuyma, 1986). Existen muchos tipos de asociaciones en los que hay interacciones de evolución recíproca entre los miembros de la asociación (por ejemplo, predador-presa, plantapatógeno, planta-polinizador, parásito-hospedero, entre otros). Esta interacción de evolución recíproca se conoce como coevolución (Carius et al. 2001).

\section{MATERIALES Y MÉTODOS}

Se realizó una revisión retrospectiva de literatura publicada en revistas y en libros especializados en parasitología y en ecología, desde los años 80 hasta la fecha, época en la que se inició el desarrollo de los conceptos teóricos de coevolución. Esta revisión permitió, a su vez, evaluar la evolución teórica sobre la interacción parásito-hospedero.

\section{TEORÍAS SOBRE IPH}

Modelos de coevolución parásito-hospedero: El término coevolución ha sido definido de diversas maneras. Por ejemplo, se ha entendido por coevolución el cambio en la estructura genética de cada una de las especies interactuantes en respuesta al cambio genético de la otra especie. Anderson (1991), por su parte, considera que la naturaleza básica del modelo de vida de un parásito supone que los parásitos y los hospederos coevolucionan de una forma dinámica. En años más recientes, Thompson (1994) aporta mayor claridad al concepto, definiéndolo como el cambio evolutivo recíproco en especies interactuantes.

Tradicionalmente, ha existido el consenso de que parásitos bien adaptados afectan poco a sus hospederos ( $\mathrm{O}^{\prime}$ Brien $\mathcal{E}$ Evermann, 1988; Lively \& Apianus, 1998), pero, actualmente, esta idea ha sido cuestionada en la medida en que estudios teóricos han indicado que muchas rutas coevolutivas se deben seguir en respuesta a las interacciones entre la patogenicidad del parásito y la eficiencia de la transmisión del patógeno al hospedero (Gulland, 1998).

Uno de los modelos de coevolución parásito-hospedero es el de coespeciación alopátrica, el cual, se basa en el supuesto que parásitos y hospederos simplemente comparten espacio y energía. De manera tal que, cuando el flujo génico en una población de hospederos es interrumpido por un evento de vicarianza (formando dos subpoblaciones), también es interrumpido el flujo génico en los parásitos, dando como resultado especiación alopátrica, tanto de la población de hospederos como en la de parásitos (Bush et al. 2001). El tiempo de la especiación para parásito y hospedero no es necesariamente el mismo y la coespeciación puede ser sincrónica o retardada (Hafner $\varepsilon$ Nadler, 1990). En la especiación sincrónica, el hospedero y el parásito se especian simultáneamente y sus linajes muestran grados similares de divergencia evolutiva. En contraste, en la coespeciación retardada uno de los miembros de la asociación se retrasa del otro. De tal forma que si la especiación del parásito se retrasa de la del hospedero, la divergencia evolutiva del primero será menor que la del hospedero.

El modelo de rastreo de recursos, se basa en el concepto ecológico de que los hospederos son parches de recursos necesarios que los parásitos rastrean a través del tiempo evolutivo (Bush et al. 2001). Bajo este escenario, los parásitos evolucionan en respuesta al cambio en el recurso ofrecido por el hospedero y, en consecuencia, si un hospedero cambia el recurso buscado por el parásito, es probable que éste sufra un cambio evolutivo que le permita explotar el nuevo recurso.

Un tercer modelo, llamado Carrera Armamentista Evolutiva (CAE), representa un punto de vista coevolutivo más estricto, pues requiere de la respuesta adaptativa mutua entre parásito y hospedero (Carius et al. 2001). El modelo asume que parásito y hospedero evolucionan constantemente de una manera agresiva el uno hacia el otro. La selección del parásito va dirigida siempre hacia una mayor explotación del hospedero, mientras que la selección en este último es siempre hacia una exclusión más efectiva del parásito. Se 
asume que las CAE ocurren en el contexto de la hipótesis gen-por-gen, que propone que por cada gen causante de la resistencia en un hospedero, hay un gen correspondiente por virulencia en el parásito. La resistencia en el hospedero y la virulencia en el parásito son los genes dominantes; de la misma forma que la susceptibilidad en el hospedero y la avirulencia en el parásito constituyen los genes recesivos (Tabla 1).
La posible secuencia de eventos para el desarrollo de una CAE requeriría de los siguientes pasos: primero, el parásito reduce la adecuación del hospedero y éste adquiere mecanismos de defensa contra el parásito, a través de mutación o de recombinación. El hospedero con este nuevo mecanismo de defensa ha aumentado su adecuación y el carácter se dispersa dentro de la población (probablemente,

Tabla 1. Resistencia y susceptibilidad esperada de un hospedero a varios genotipos de parásito en el contexto de la hipótesis gen-por-gen (Tomado de Bush et al. 2001).

\begin{tabular}{|l|l|l|l|}
\hline & \multicolumn{3}{|c|}{ Genotipo del Hospedero** } \\
\hline Genotipo del Parásito* & $\mathrm{RR}$ & $\mathrm{Rr}$ & $\mathrm{Rr}$ \\
\hline $\mathrm{AA}$ & Hospedero resistente & Hospedero resistente & Hospedero susceptible \\
\hline $\mathrm{Aa}$ & Hospedero resistente & Hospedero resistente & Hospedero susceptible \\
\hline $\mathrm{Aa}$ & Hospedero susceptible & Hospedero susceptible & Hospedero susceptible \\
\hline
\end{tabular}

*A, gen dominante del parásito que confiere virulencia; a, gen recesivo del parásito que confiere avirulencia.

${ }^{*} \mathrm{R}$, gen dominante del hospedero que confiere resistencia al parásito; r, gen recesivo del hospedero que confiere susceptibilidad.

una nueva especie de hospedero). Eventualmente, una nueva mutación o recombinación aparece en la población del parásito y lo hace capaz de superar la nueva defensa. Si esta contra-defensa aumenta, la adecuación del parásito, se esparcirá en la población (probablemente, una nueva especie de parásito) y será capaz de parasitar al grupo antes protegido. Bajo este orden de ideas, el ciclo se repetirá de nuevo (Bush et al. 2001).

No obstante, lo anterior supone una debilidad a la teoría de coevolución parásito-hospedero y es que la mayoría de los modelos de evolución de parásitos presumen que la población hospedera es homogénea en sus características de resistencia; sin embargo, se ha demostrado que algunos hospederos pueden diferir en su habilidad para resistir al efecto del parásito (Gandon E van Zant, 1998; Gandon et al. 2002).

Por otro lado, se ha advertido que dos procesos distintos, coacomodación, proceso de reconciliación entre el parásito y el hospedero, que permite la coexistencia. y coespeciación, que ocurre en conjunto, debido a la especiación del hospedero o independientemente, estableciéndose tanto en diferentes especies de hospedero o en sitios diferentes o en el mismo hospedero, habían sido frecuentemente tomados erróneamente como coevolución y, por el contrario, deberían ser diferenciados entre sí (Stuart E Strier, 1995).
El resultado de las interacciones parásito-hospedero (IPH): Hasta la década de los 60, el paradigma para los parasitólogos era que en el tiempo evolutivo, las IPH evolucionaran casi invariablemente hacia el comensalismo (Gandon et al. 2002). En este contexto, las IPH actuales en las que el parásito es altamente patógeno eran vistas como relativamente nuevas en el tiempo evolutivo o, incluso, ecológico. Esta perspectiva implica que las relaciones antagonistas parásito-hospedero están o en camino de extinguir a uno o ambos participantes o evolucionando a una interacción más suave. Desde entonces, la síntesis gradual de estudios ecológicos, evolutivos y de genética de poblaciones han cambiado esta perspectiva y este paradigma ha sido reemplazado por la perspectiva de que todos los resultados son posibles, del comensalismo a un gran antagonismo (Thompson, 1994).

El paradigma clásico de la IPH evolucionando, exclusivamente a un resultado benigno, se basa en el supuesto que un parásito que causa poco daño representa una ventaja, tanto al hospedero como al parásito. La mayoría de la evidencia que apoya este concepto proviene de observaciones de parásitos menos patógenos en su hospedero regular que en hospederos nuevos, introducidos en su rango de distribución y parásitos recién evolucionados, altamente patógenos, se vuelven gradualmente más benignos (Bush et al. 2001; Cunningham et al. 2003). Por ejemplo, en el Este de África los rumiantes nativos sufren infecciones suaves con morbilidad insignificante, debido al hemoflagelado Trypanosoma 
brucei; en contraste, los rumiantes domésticos introducidos que han sido criados en el área por largo tiempo desarrollan síntomas más serios y los animales recién importados sufren de infecciones típicamente fatales (Allison, 1982).

Sin embargo, los parásitos introducidos (o asociaciones parásito-hospedero nuevas) no siempre son más dañinas que los parásitos adaptados. Existe evidencia del caso opuesto: los parásitos nuevos parecen menos dañinos, menos infecciosos y menos adecuados que los mismos parásitos que infectan el hospedero, al cual, están adaptados. La explicación de la alta patogenicidad observada en asociaciones nuevas puede ser sencilla. Es probable que estos casos sean excepciones que han sido notadas, debido a sus efectos extremos, mientras que otras numerosas asociaciones nuevas han pasado inadvertidas por su benignidad. Es también probable que lo que se observa como una alta virulencia en la introducción de algunos parásitos sea simplemente una respuesta ecológica a una interacción ecológica nueva de dos poblaciones no ajustadas y no una respuesta evolutiva de la interacción (Bush et al. 2001).

Los puntos de vista actuales indican que el resultado de las IPH representa un continuo, desde el antagonismo hasta el mutualismo, dependiendo de la historia natural de los organismos involucrados, con énfasis en la forma de transmisión y reproducción (Gandon et al. 2002).

Algunas de las ideas prevalecientes afirman que los distintos niveles de reproducción y de patogenicidad del parásito dependen del grado al que los costos y beneficios de la reproducción extensiva varían entre diferentes especies de parásitos. Por ejemplo, debido a que los hospederos son islas temporales para los parásitos, la transmisión efectiva de un hospedero a otro es esencial para la supervivencia de su material genético.

De igual forma, la reproducción extensiva de un parásito dentro de un hospedero aumentará el número de parásitos disponibles para infectar a otros hospederos. Si esto ocurre, la reproducción de los hospederos se puede ver afectada de manera adversa y su inmovilización o muerte reducirán la probabilidad del parásito de infectar a otros.

Por otro lado, si los parásitos son transmitidos por vectores, la inmovilización del hospedero aumentará su probabilidad de ser picado y una reproducción extensiva por parte del parásito resultará benéfica, pues aumentará la probabilidad de infectar al vector. En resumen, la reducción de la movilidad de los hospederos debe ser costosa para los parásitos que dependen de ella para su transmisión; estos parásitos, entonces, deben tener una menor virulencia; no obstante, si la movilidad del hospedero no afecta la transmisión del parásito, la adecuación de este último no se verá afectada por la falta de movilidad del primero y la selección natural favorecerá un alto nivel de explotación del hospedero y aumentará la virulencia (Ewald, 1995).

A partir de información sobre tasas de mortalidad de enfermedades humanas como estimador de la patogenicidad, Ewald (1995) demostró que las enfermedades transmitidas por insectos eran significativamente más letales que las transmitidas sin vectores intermedios. De manera similar, usando la inmovilización del hospedero como indicador de patogenicidad, concluyó que las enfermedades transmitidas por vectores fueron significativamente más letales.

No todos los parásitos que dependen de vectores para su transmisión muestran el mismo patrón. La variabilidad relacionada con la historia natural de las IPH puede cambiar significativamente el resultado de la interacción. Mock $\mathcal{E}$ Gill (1984) estudiaron la dinámica de la relación entre el tritón de manchas rojas Notophtalmus viridescens y el tripanosoma Trypanosoma diemyctyli. El estudio indicó que el parásito no aumentaba la mortalidad ni la habilidad reproductiva del hospedero. Las sanguijuelas acuáticas son los vectores para este hemoparásito, lo que ocasiona que sólo cuando son juveniles y tienen ciclos de vida semiacúaticos pueden ser infectados los individuos de la especie. Parece ser que el intervalo de tiempo potencial entre eventos de transmisión (los años pasados fuera del agua como adultos) introdujo una fuerte presión de selección contra los tripanosomas patogénicos. Los tritones parasitados con tripanosomas patogénicos, probablemente, murieron antes de regresar al agua a reproducirse y pasar la infección. Sólo los tritones con hemoparásitos menos patógenos sobrevivieron lo suficiente para regresar al agua.

Variación en los caracteres de historia de vida por parasitismo: La evolución de las IPH no se restringe a consideraciones coevolutivas. Fuera de los límites de la asociación histórica o estricta filogenia, existe un amplio arreglo de interacciones que merecen atención de la perspectiva evolutiva.

Precisamente, los efectos directos de los enemigos naturales (parásitos, patógenos, herbívoros) en los caracteres de historia de vida (crecimiento y reproducción) de sus hospederos están bien documentados: si caracteres particulares de la historia de vida del hospedero resultan en genotipos más susceptibles o más resistentes al parasitismo, estos enemigos naturales pueden afectar la evolución de la historia de vida de los hospederos. Primero, la historia de vida en sí puede ser la base de la resistencia o tolerancia del hospedero $\mathrm{y}$, segundo, los caracteres de historia de vida pueden estar genéticamente correlacionados con caracteres relacionados a la resistencia (Koskela, 2002). 
Como ejemplo de caracteres de historia de vida que confieren resistencia, las flores de vida corta de Silene sp. tienen menor riesgo de infección por el hongo Microbotryum violaceum que las flores de vida más larga, por lo tanto, se espera selección por los tiempos de vida florales cortos cuando el riesgo de infección es alto (Shykoff et al. 1996). Una correlación entre la resistencia y la historia de vida del hospedero se ha encontrado en un experimento de selección con el mosquito Aedes aegypti donde la resistencia contra la infección de malaria se correlacionó negativamente con el tiempo de desarrollo y el tamaño del adulto (Yan et al. 1997). Por otra parte, en un estudio con plantas originarias de ocho poblaciones de Urtica dioica, cuatro parasitadas y cuatro no parasitadas por la planta holoparasítica Cuscuta europeae se observó que las primeras florecieron posteriormente y asignaron menos biomasa a la reproducción asexual comparadas con las segundas. Estos resultados indican que la selección por el parásito puede haber favorecido el florecimiento tardío y puede haber selección en contra de la reproducción asexual (Koskela, 2002). El estudio realizado en los grillos de la especie Acheta domesticus demuestran también un aumento en la postura de huevos, debido a la infección fatal de la bacteria Serratia marcescens, lo que apoya la hipótesis que los animales infectados pueden aumentar su productividad reproductiva para compensar su probable pérdida en el futuro, por la enfermedad (Adamo, 1999).

Parásitos y la evolución del sexo: Desde un punto de vista evolutivo, el sexo es una mala idea. Es un proceso costoso en términos de energía y los organismos que se reproducen sexualmente son la mitad de exitosos propagando sus genes que los que no lo hacen. Entonces, cंpor qué existe la reproducción sexual? Una ventaja es la recombinación genética, que aumenta la diversidad génica y asegura la variabilidad, además de purgar mutaciones deletéreas.

Diversas hipótesis han sido propuestas, pero la mayoría caen en una de dos clases. Algunas hipótesis atribuyen el mantenimiento del sexo a la heterogeneidad ambiental en el tiempo o en el espacio. En estos casos, la variabilidad asegurará que al menos algunos genotipos sean exitosos en ambientes variables. Las otras, se atribuyen a las IPH.

Dos hipótesis han sido propuestas sobre los efectos de los parásitos en los caracteres de historia de vida de sus hospederos. Primero, la reproducción sexual será favorecida sobre la asexual cuando el riesgo de infección es alto, dado que la progenie producida sexualmente debe ser más apta para evadir los parásitos que coevolucionan. De acuerdo a la Hipótesis de la Reina Roja (HRR), los parásitos pueden ejercer una fuerte selección sexual dependiente de la frecuencia de encuentros sexuales y los procesos de selección sexual que favorecen genotipos raros (esta hipótesis sería, en realidad, una CAE más específica) (Lythgoe, 2000). En síntesis, la HRR predice cambio evolutivo continuo (de hospedero y de parásito), bajo condiciones constantes en el ambiente físico. El nombre de la hipótesis proviene del libro de Lewis Carroll A través del espejo, que dice que se debe seguir corriendo para simplemente permanecer en el mismo lugar (Martens E Schön, 2000).

La segunda hipótesis predice que un alto riesgo de infección favorecerá la reproducción temprana, especialmente, si la infección tiene efectos dañinos fuertes en la viabilidad del hospedero (por ejemplo, resulta en castración o en muerte del hospedero) o si la preferencia de la infección aumenta con la edad. Los estudios comparativos entre poblaciones han aportado evidencias para ambas hipótesis (Scott, 1988).

Si el sexo es una adaptación contra parásitos debe ser común donde los parásitos son usuales. En Nueva Zelanda, por ejemplo, las poblaciones del caracol dioico de agua dulce Potamopyrgus antipodarum están formadas por individuos sexuales y partenogenéticos; Lively (1992) encontró una correlación positiva entre la frecuencia de reproducción sexual en individuos partenogenéticos y el grado de infección por platelmintos de la clase digenea. En poblaciones donde los parásitos son raros, las hembras partenogenéticas habían reemplazado numéricamente a las sexuales, mientras que en poblaciones donde los parásitos eran comunes las hembras sexuales persistían. En otro estudio, se llegó a conclusiones similares, mientras se investigaba el parasitismo en formas sexuales e híbridos partenogenéticos coexistentes de Poecilopsis monarca, en México (Lively et al. 1990). Los clones partenogenéticos acumulaban parásitos a una mayor tasa que la forma sexual. Si las poblaciones sexuales eran llevadas a endogamia, los efectos antiparasíticos de la reproducción sexual desaparecían, debido a la baja diversidad. Por otro lado, si otros individuos del huésped entraban en la población, el parasitismo declinaba, por un aumento en la diversidad génica. Cabe mencionar que el hecho que los individuos partenogenéticos fueran híbridos puede haber afectado la susceptibilidad a parásitos.

Aunque estos ejemplos proveen evidencia de la presentación de menor parasitismo en poblaciones de reproducción sexual que en aquellas partenogenéticas, no existía evidencia clara para la predicción de selección dependiente de frecuencia, en la que los genotipos raros son seleccionados a favor y los comunes en contra. Dybdahl \& Lively (1998), estudiando por un periodo de cinco años linajes clonales del caracol Potamopyrgus antipodarum y sus parásitos digeneanos, identificaron marcadores genéticos específicos a cada clon. Con ellos, identificaron clones raros y comunes y siguieron sus frecuencias de presentación y las de sus parásitos, a través 
del tiempo. En el periodo del estudio, los clones mostraron la oscilación característica de la selección dependiente de frecuencia de presentación, con ciclaje de clones hospederos y respuestas correlacionadas retardadas en el tiempo por los parásitos. Por ejemplo, uno de los clones comunes infectados fue disminuido en la población y reemplazado por lo que, originalmente, era un clon raro, que también sufrió el mismo proceso posteriormente. Estos clones fueron experimentalmente expuestos al parásito común. En el laboratorio, los clones hospederos que habían sido raros durante los cinco años previos fueron significativamente menos infectados que los clones comunes. Este estudio prueba que los genotipos raros tienen mayor probabilidad de escapar a la infección y que las IPH pueden producir oscilaciones dependientes de la frecuencia de presentación en la población de hospederos.

En otro estudio, Agrawal $\mathcal{E}$ Lively (2001) mostraron los efectos de los parásitos en la evolución de la autofertilización evaluando los efectos de la coevolución parásito-hospedero sobre la dispersión de alelos para autofertilización del hospedero, usando modelos de simulación. Se consideraron cuatro modelos genéticos diferentes y se variaron el nivel de pérdida de gametos masculinos, la virulencia de la infección y el grado de autofertilización del parásito. Se halló que los altos niveles de virulencia de los parásitos favorecían la endogamia; aunque ésta interactuaba fuertemente con la pérdida de gametos masculinos, con la base genética de la infección y con el grado de autofertilización del parásito. En resumen, los parásitos pueden ser una fuerza efectiva al detener la dispersión de los alelos de autofertilización, pero los resultados dependen fuertemente de las características del sistema.

Un estudio con poblaciones del gasterópodo de agua dulce Campeloma limun (Johnson, 2000) presenta resultados consistentes con dos de las predicciones de la HRR: los individuos partenogénicos persisten en la ausencia de parásitos, pero son sobreexplotados cuando los presentan. En este estudio realizado sobre poblaciones partenogénicas y sexuales, se observó que los individuos sexuales muestran niveles intermedios de parasitismo y que la reproducción sexual puede proveer un escape temporal de los parásitos. Debido a que el hospedero y el tremátodo que lo parasita indican tiempos generacionales similares, la reproducción sexual puede prevenir el rastreo y la sobreexplotación de los genotipos más comunes de hospedero.

De igual forma, la HRR, como explicación para la prevalencia de la reproducción sexual, también ha sido motivo de diversas críticas en los últimos años. Esto es a que, idealmente, cualquier tipo de coevolución, incluida la HRR, requiere de pares únicos de especies interactuantes y el proceso se diluye cuando especies adicionales se involucran (Thompson, 1994).

West et al. (1999) argumentaron que es muy probable que se requiera más de un mecanismo para explicar la prevalencia del sexo. Sugirieron un punto de vista pluralista, combinando la coevolución de la HRR con hipótesis basadas en mutaciones, lo que representará ventajas sobre las hipótesis propuestas en contra. Ampliar el concepto de la HRR a todas las interacciones bióticas, incluyendo predadores y competidores, reforzará la hipótesis de prevalencia de reproducción sexual.

Parasitismo y poliandria: En muchas especies animales, por ejemplo, en insectos (Scarpassa et al. 1992) y en aves (Owens, 2002), las hembras se aparean típicamente con más de un macho (poliandria). Diversas hipótesis sugieren las ventajas de este comportamiento reproductivo para las hembras. Una de éstas, conocida como la hipótesis de variabilidad genética contra parásitos, afirma que la poliandria es un mecanismo de defensa contra parásitos, debido a que los múltiples apareamientos aumentan la variabilidad genética (Sherman et al. 1988; Baer E Schmid-Hempel, 1999). Dada una selección dependiente de frecuencias negativas de parásitos hacia sus hospederos, la poliandria podría inducir una ventaja selectiva al producir descendencia con genotipos raros. Esta hipótesis ha sido apoyada por varios estudios, por ejemplo, en condiciones de campo, se observó que la variabilidad genética en colonias de Bombus terrestris reduce el parasitismo al compararlo con colonias originadas de hembras monándricas (Baer E Schmid-Hempel, 2001). Esta relación entre adecuación y heterogeneidad genética implica consecuencias importantes para la evolución y el mantenimiento de la poliandria. Este estudio aporta también evidencia para la HRR.

Parásitos y selección sexual: Hamilton E Zuk (1982) llamaron la atención sobre el papel potencial de los parásitos en la selección sexual. Propusieron que los caracteres sexuales secundarios, como los colores brillantes y los despliegues de cortejo de muchas especies animales, permiten a las hembras evaluar en su potencial pareja reproductiva la habilidad para resistir parásitos. Al aparearse con estos machos, las hembras asegurarían pasar los genes de la resistencia a su descendencia. Esta hipótesis se basa en tres supuestos: 1) el despliegue de los caracteres sexuales secundarios de un individuo se relaciona con su salud y vigor general; 2) los hospederos evolucionan con los parásitos y como resultado constantemente generan resistencia heredable $\mathrm{y}, 3$ ) los parásitos tienen un efecto negativo en la viabilidad de los hospederos. La evidencia disponible parece apoyar los supuestos anteriores. 
Existen tres modelos básicos de selección sexual mediada por parásitos que puede resultar en cambios adaptativos en la elección de pareja. 1) los individuos pueden evitar aparearse con individuos infectados con parásitos transmitidos por contacto (piojos y parásitos causantes de enfermedades de transmisión sexual), que pueden ser transmitidas a la descendencia; 2) en especies, en las cuales, el macho proporciona cuidado parental, las hembras deben escoger compañeros saludables y vigorosos para ayudar al cuidado de la descendencia y, 3) si la resistencia a los parásitos es heredable, las hembras, se deberán aparear con machos resistentes para obtener genes resistentes para su descendencia. Este último modelo, donde existe resistencia basada en la genética, es un ejemplo del modelo buenos genes de selección sexual, pues la elección de la hembra lleva a descendencia más variable con adecuación aumentada (Bush et al. 2001).

La hipótesis de Hamilton E Zuk (1982) para la evolución de los caracteres sexuales secundarios, cuando permiten a las hembras evaluar la habilidad del compañero potencial a resistir parásitos, sugiere que en especies, particularmente vulnerables al parasitismo, la selección sexual deberá favorecer un mayor desarrollo de los caracteres certificado de salud, permitiendo a las hembras una evaluación más precisa de la carga parasitaria del macho (Kelly et al. 2001).

Hamilton \& Zuk (1982), originalmente, apoyaron sus hipótesis con observaciones de una asociación positiva entre la prevalencia de hemoparásitos (Leucocytozoon sp., Haemoproteus sp., Plasmodium sp., Tripanosoma sp., Toxoplasma sp. y microfilarias) y tres tipos de despliegue de los hospederos (brillantez masculina y femenina y complejidad de la vocalización) en aves paseriformes. Precisamente, estos despliegues son caracteres de certificado de salud, que inciden sobre la selección sexual.

Asimetría fluctuante y parasitismo: Bajo condiciones ideales, un embrión desarrolla simetría bilateral perfecta; sin embargo, ciertas perturbaciones durantes el desarrollo pueden ocasionar desviaciones de la asimetría en algunos caracteres. La asimetría fluctuante mide estas pequeñas desviaciones al azar en un carácter morfológico dado. Los factores que afectan la estabilidad del desarrollo son bien conocidos e incluyen el parasitismo (Palmer, 1994). La asimetría fluctuante puede ser importante en la selección sexual. Diversos estudios sugieren que los individuos más simétricos tienen mayor adecuación (Grether, 1997; Pither $\mathcal{E}$ Taylor, 2000; Benítez et al. 2008).

Thornhill (1992) discutió la idea que los parásitos puedan estar involucrados en la producción de asimetría fluctuante. Los parásitos pueden causar asimetría fluctuante al competir con sus hospederos por nutrientes disponibles durante su desarrollo, comprometiendo su metabolismo, su desarrollo, su tasa de crecimiento, entre otros. Además, el parásito puede ser responsable de efectos patológicos específicos en ciertas partes del cuerpo del hospedero que, eventualmente, ocasionarán asimetría fluctuante. Si los parásitos aumentan la asimetría fluctuante de sus hospederos pueden afectar así su éxito de apareamiento. Si la simetría es un indicativo de genes buenos, las hembras podrán usarla para evaluar la calidad de sus parejas. Más aún, si el parasitismo aumenta la asimetría fluctuante, la selección sexual favorecerá a los individuos libres de parásitos y esto podría resultar en la evolución de resistencia a parásitos (Polak, 1997).

Aunque existe evidencia que la asimetría fluctuante tiene un efecto negativo en el éxito reproductivo y que los parásitos aumentan la asimetría fluctuante de sus hospederos, el efecto de los parásitos en el éxito reproductivo, debido a asimetría fluctuante inducida, no ha sido demostrado definitivamente.

Parasitismo y aislamiento reproductivo: Algunos parásitos pueden causar incompatibilidad reproductiva entre poblaciones de hospederos. La bacteria Wolbachia es común a un gran número de artrópodos, su transmisión es principalmente vertical y es causante de incompatibilidad reproductiva en el hospedero. El cruce entre machos y hembras infectados no se ve afectado y resulta en descendencia viable; no obstante, si el apareamiento ocurre entre hembras no infectadas y machos infectados, la bacteria causa incompatibilidad citoplásmica al impedir la incorporación de los cromosomas masculinos al óvulo fertilizado y el desarrollo se interrumpe. Si los hospederos son tratados con antibióticos que acaben con la bacteria, la incompatibilidad desaparece y el aislamiento reproductivo termina. Desde un punto de vista evolutivo, si el aislamiento reproductivo entre poblaciones es mantenido a lo largo del tiempo, ocurrirán fenómenos de especiación (Thompson, 1994).

Tres diferentes tipos de especiación inducida por parásitos han sido propuestos basados en la reducción de la viabilidad o la fertilidad de los hospederos (Thompson, 1987). En una interacción, un parásito heredado citoplasmáticamente reduce la viabilidad o fertilidad de los híbridos en cruzas entre poblaciones incompatibles y ocurre especiación por inferioridad de los híbridos. También es posible que el parásito cause esterilidad en los machos de algunas poblaciones, favoreciendo la evolución de especies hermanas partenogénicas. En una tercera interacción, un parásito heredado no citoplásmico como Plasmodium sp. puede tener un efecto detrimental mayor en algunas poblaciones que en otras, favoreciendo una vez más el proceso de especiación, por selección, contra organismos híbridos. 
La idea de coevolución parásito-hospedero y una simultánea especiación ha sido uno de los conceptos unificadores de la parasitología, hasta tal punto que se ha formalizado en una serie de leyes que se complementan y no son excluyentes entre sí, como se presentan en la tabla 2.
Transferencia génica: La teoría evolutiva interpreta la evolución como el producto de variación generada por mutación al azar y recombinación, con la selección natural actuando en la variación producida; sin embargo, en años recientes, la idea de transferencia génica horizontal ha recibido mucha atención. La transferencia génica horizontal se define como

Tabla 2. "Reglas" en el estudio de coevolución parásito-hospedero (Tomado de Stuart E Strier, 1995).

\begin{tabular}{|l|l|}
\hline Regla de Farenholz & La filogenia del parásito semeja la filogenia del hospedero. \\
\hline Regla de Szidat & Entre más primitivo es el hospedero más primitivos son los parásitos que él alberga. \\
\hline Reglas de Manter & $\begin{array}{l}\bullet \text { Los parásitos evolucionan más lentamente que los hospederos. } \\
\text { por un grupo de parásitos. } \\
\bullet \text { Una especie de hospedero alberga el mayor número de especies de parásitos en el área donde } \\
\text { han residido por el mayor tiempo, de tal forma que si la misma o dos especies de hospederos } \\
\text { relacionadas exhiben la misma distribución y fauna de parásitos, las áreas en las cuales los } \\
\text { hospederos ocurren deben haber sido contiguas en el pasado. }\end{array}$ \\
\hline Regla de Eichler & $\begin{array}{l}\text { Entre mayor sea el número de parásitos que un hospedero alberga mayor es el grupo sistemático, } \\
\text { al cual, el hospedero pertenece. }\end{array}$ \\
\hline
\end{tabular}

la transferencia no sexual de información genética entre los genomas de organismos de diferente especie.

Se sabe que este fenómeno ocurre, principalmente, en organismos procariotes, pero la transferencia entre procariotes y eucariotes y entre eucariotes parece haber ocurrido también (Kidwell, 1993). El mecanismo para la transferencia horizontal de genes entre procariotes incluye transformación, conjugación y transducción; no obstante, en eucariotes, normalmente se requiere un vector para transportar las secuencias de ADN entre especies reproductivamente aisladas. Varios virus y posiblemente un ácaro han sido identificados como vectores efectivos (Bush et al. 2001).

La idea de transferencia génica en IPH fue introducida por Howell (1985), basada, principalmente, en la habilidad de algunos parásitos de producir moléculas similares a las de su hospedero (antígenos) y así evitar el reconocimiento. Tal fenómeno sería posible si los parásitos tienen genomas con secuencias de ADN idénticas o cercanamente relacionadas a la del hospedero (ADN homólogo). Este tipo de homología podría ser el producto de conservación a largo plazo o de un cambio adaptativo más reciente, a través de mutación, de recombinación y de selección. Howell (1985) indica que estas homologías en el ADN pueden ser el producto de la incorporación directa del material genético del hospedero al genoma del parásito. Este proceso de transferencia genética interespecífica puede ser un flujo bidireccional de hospedero a parásito y viceversa. La incorporación del material genético del parásito por el hospedero puede llevar a la tolerancia del parásito. Por otro lado, la incorporación del ADN del hospedero por el parásito puede llevar a la expresión de macromoléculas por el parásito, facilitando la evasión de la respuesta inmune.

En la actualidad, la evidencia para este fenómeno entre parásitos y hospederos es poca y no existe evidencia directa de este intercambio génico. Evidencia circunstancial incluye la similitud entre el colágeno humano y el de Ascaris (Michaeli et al. 1972), la habilidad de Fasciola hepatica de sintetizar substancias de la sangre humana (Damian, 1979) y la presencia de ADN de ratón en uno de sus parásitos, Schistosoma japonicum (Iwamura et al. 1991). En este último caso, el ADN del hospedero fue aparentemente integrado al genoma de adultos parásitos y fue detectable en los huevos.

Existe un caso bien documentado, en el que un ácaro semiparasítico, Proctolaelaps regalis, logró la transferencia de genes entre dos especies de Drosophila, alimentándose de los huevos de Drosophila sp. perforando los huevos 
cercanos con sus quelíceros (Houck, 1994). Este comportamiento de alimentación provee potencial para la transferencia de inclusiones celulares, conteniendo ADN, de un hospedero a otro, conforme los huevos son perforados y el material de uno es accidentalmente transferido a otro. Este comportamiento simula la microinyección de huevos usados por investigadores en la transferencia de genes intra e interespecífica en Drosophila sp.

En resumen, la transferencia horizontal de genes entre parásito y hospedero es una fuente potencial de variación sobre la que la selección natural puede operar. Aún si la frecuencia del fenómeno es baja puede tener un profundo impacto en la filogenia de muchos grupos (Rhode, 1990). En este contexto, la sistemática filogenética basada en datos moleculares no sería totalmente confiable, debido a la posible transferencia genética entre especies no relacionadas. Bajo esta perspectiva, el mosaico evolutivo (con la transferencia genética actuando como fuente de unidades evolutivas aisladas) podría explicar, por ejemplo, la evidencia contradictoria en las relaciones de algunos taxa parasíticos (Bush et al. 2001).

Tanto el modelo de pares únicos como el de multiparásitos, se restringe a parásitos y, por lo tanto, sólo considera las defensas relacionadas con la interacción parásito-hospedero. Una evaluación correcta de la importancia de la HRR requiere que todos los tipos de defensa se consideren, así como sus costos y compromisos, lo que debilita la hipótesis pues todas las defensas provienen de la misma poza de recursos comunes (Martens E Schön, 2000).

\section{Conclusiones}

La revisión y la discusión realizada sobre las teorías existentes sobre la evolución de las IPH permiten concluir que está sujeta a estudios que las apoyan y a otros que la critican. Lo anterior es en parte, debido a los diferentes grados de especialismo y generalismo exhibidos por varios taxa de parásitos hacia sus hospederos intermediarios y definitivos. Adicionalmente, se debe a que, a pesar que las técnicas de sistemática filogenética han producido interesantes ejemplos de radiación conjunta en algunos grupos de hospederos sujetos a un vasto estudio (por ejemplo, Enterobius y primates), la mayoría de especies de parásitos aun deben ser descritas por la sistemática. Esto evidencia la falta de información que, a la larga, puede generar sesgos potenciales en estudios que pretendan construir filogenias coevolutivas en grupos de hospederos poco estudiados.

Algunos principios modernos ecológicos y evolutivos sugieren que la aplicación de los conceptos generales de coevolución parásito-hospedero no son siempre justificados. Quizás porque la información disponible es incompleta, se desconoce la especificidad que muchos parásitos pueden tener por algunos hospederos y la presencia o ausencia de un hospedero intermediario en el ciclo de vida de un parásito puede afectar el nivel de coespeciación con el hospedero definitivo. Adicionalmente, la presencia o ausencia de especies de parásitos en un hospedero determinado puede reflejar factores ecológicos más que coevolución per se.

Bajo este contexto, la evolución de las IPH es compleja pues, la interacción en sí misma, es un evento complejo. Los parásitos, generalmente, evolucionan a una tasa de transmisión máxima justo por debajo del límite de extinción del hospedero, es decir, los parásitos no evolucionan a una tasa de infección lo suficientemente alta para causar extinción de sus hospederos y, por lo tanto, de sí mismos.

A pesar de los estudios en contra de la teoría de coevolución hospedero-parásito, el uso de información sobre la ocurrencia de parásitos permite evaluar eventos evolutivos. De ahí que se pueda estimar el origen de un taxón en ausencia de registro fósil y determinar su biogeografía. De la misma forma, es posible clarificar la naturaleza de una serie de eventos de colonización y especiación; sin embargo, el tener clara esta generalidad es sólo un primer paso hacia el sinfín de posibles resultados evolutivos de la interacción. Como se ha visto antes, tal interacción se puede complicar en gran manera al considerar otros factores, como las interacciones con otros parásitos dentro de un mismo organismo o la influencia de factores genéticos, ambientales y ecológicos en estas interacciones.

Agradecimientos: A los árbitros quienes revisaron el manuscrito inicial. Conflicto de intereses: El manuscrito fue revisado y preparado por el autor quien declara que no existe ningún conflicto de intereses que ponga en riesgo los resultados presentados.

\section{BIBLIOGRAFÍA}

1. ADAMO, S.A. 1999. Evidence for adaptative changes in egg laying in cricket exposed to bacteria and parasites. Animal Behaviour. 57:117-124.

2. AGRAWAL, F.A.; LIVELY, C.M. 2001. Parasites and the evolution of self- fertilization. Evolution. 55(5):869-879.

3. ALLISON, A.C. 1982. Coevolution between host and infectious diseases agents and its effects on virulence. En : Anderson, R.M.; May, R.M. eds. Population biology of infectious diseases. Oxford University Press, (Oxford, USA). p.245-268. 
4. ANDERSON, R.M. 1991. Populations and infectious diseases: ecology or epidemiology? J. Animal Ecol. 60:1-50.

5. BAER, B.; SCHMID-HEMPEL, P. 1999. Experimental variation in polyandry affects a parasite loads and fitness in a bumblebee. Nature. 397:151-154.

6. BAER, B.; SCHMID-HEMPEL, P. 2001. Unexpected consequences of polyandry for parasitism and fitness in the bumblebee (Bombus terrestris). Evolution. 55(8):1639-1643.

7. BARLOW, N.D. 1996. The ecology of wildlife disease control: simple models revisited. J. Appl. Ecol. 33:303314.

8. BEGON, M.; HARPER, J.L.; TOWNSEND, C.R. 1986. Ecology: Individuals, populations and communities. Blackwell Science Publications. (New York, USA). 486p.

9. BENIITEZ, H.; BRIONES, R.; JEREZ, V. 2008. Asimetría fluctuante en dos poblaciones de Ceroglossus chilensis (Eschscholtz, 1829) (Coleoptera: Carabeidae) en el agroecosistema Pinus radiata D. Don región del BioBio, Chile. Gayana. 72(2):131-139.

10. BOOTS, M.; SASAKI, A. 2001. Parasite-driven extinction in spatially explicit host-parasite systems. Am. Naturalist. 34(12):706-713.

11. BUSH, A.O.; FERNÁNDEZ, J.C.; ESCH, G.W.; SEED, J.R. 2001. Parasitism. The diversity and ecology of animal parasites. Cambridge University Press. (Cambridge, UK). 566p.

12. CARIUS, H.J.; LITTLE, T.J.; EBERT, D. 2001. Genetic variation in host-parasite association: potencial for coevolution and frequency-dependent selection. Evolution. 55(6):1136-1145.

13. CUNNINGHAM, A.; DASZAK, P.; RODRÍGUEZ, J. 2003. Pathogen pollution: defining a parasitological threat to biodiversity conservation. J. Parasitol. 89 (Suppl.):S78-S83.

14. DAMIAN, R.T. 1979. Molecular mimicry in biology adaptation. En: Nickol, B.B. ed. Host-Parasite Interfaces. Academic Press. (USA). p.103-126.

15. DASZAK, P.; CUNNINGHAM, A.; HYATT, A. 2003. Infectious disease and amphibian population declines. Diversity and Distributions. 9:141-150.
16. DYBDAHL, M.F.; LIVELY, C.M. 1998. Host-parasite coevolution: Evidence for rare advantage and time lagged selection in a natural polulation. Evolution. 52:1057-1066.

17. DOBSON, A.P.; HUDSON, P.J. 1992. Regulation and stability of a free-living host-parasite system: Trichostrongylus tenuis in red grouse. II. Population models. J. Anim. Ecol. 61:487-498.

18. EWALD, P.W. 1995. The evolution of virulence: a unifying link between parasitology and ecology. J. Parasitol. 81:659-669.

19. FUTUYMA, D.J. 1986. Evolutionary Biology. Sinauer Associates. (USA).

20. GANDON, S.; AGNEW, P.; MICHALAKIS, Y. 2002. Coevolution between parasite virulence and host lifehistory traits. Am. Natural. 160(3):374-387.

21. GANDON, S.; VAN ZANDT, P.A. 1998. Local adaptation and host-parasite interactions. Trends in Ecology and Evolution. 13(6):214-216.

22. GRETHER, G.F. 1997. Survival cost of an intrasexual selected ornament in a damselfly. Proc. Royal Soc. London 264:207-210.

23. GULLAND, F.M.D. 1998. Impact of infectious diseases of wild animal population - a review. En: Grenfell, B.T.; Dobson, A.P. eds. Ecology of infectious diseases in natural populations. Cambridge University Press. (Cambridge, U.K). p.20-51.

24. HAFNER, M.S.; NADLER, S.A. 1990. Cospeciation in host-parasite assemblages: comparative analysis of rates of evolution and timing of cospeciation events. Syst. Zool. 39:192-204.

25. HAMILTON, W.D.; ZUK, M. 1982. Heritable true fitness and bright birds: a role for parasites? Science. 218:384387.

26. HOUCK, M.A. 1994. Mites as potencial horizontal transfer vector of eukatyotic mobile genes: Proctolaelaps regalis as a model. J. Parasitol. 80:457-469.

27. HOWELL, M.J. 1985. Gene exchange between hosts and parasites. Internal J. Parasitol. 15: 597-600.

28. IWAMURA, Y.; IRIE, Y.; KOMINAMI, R.; NARA, T.; YASURAOKA, K. 1991. Existence of host-related DNA 
sequences in the schistosome genome. Parasitol. 102:397-403.

29. JOHNSON, S.G. 2000. Population structure, parasitism, and survivorship of sexual and autodiploid parthenogenetic Campeloma limun. Evolution. 54(1):167-175.

30. KELLY, A.; HATCHER, M.J.; EVANS, L.; DUNN, A.M. 2001. Mate choice and mate guarding under the influence of a vertically transmited, parasitic sex ratio distorter. Anim. Behaviour. 61:763-770.

31. KIDWELL, M.G. 1993. Lateral transfer in natural populations of eukariotes. Ann. Rev. Genetics. 27:235256.

32. KOSKELA, T. 2002. Variation in life-history traits among Urtica dioica populations with different history in parasitism by the holoparasitic plant Cuscuta europeae. Evol. Ecol. 16:433-454.

33. LIVELY, C.M. 1992. Parthenogenesis in a freshwater snail: reproductive assurance versus parasitic release. Evolution. 46:907-913.

34. LIVELY, C.; APANIUS, V. 1998. Genetic diversity in hostparasite interactions. p. 421-449. En: Grenfell, B.; Dobson, A. eds. Ecology of infectious diseases in natural populations. Cambridge University Press. (Cambridge, RU). p.421-449.

35. LIVELY, C.M.; CRADOCCI, C.; VRIJENHOEK, R.C. 1990. Red Queen Hypothesis supported by parasitism in clonal and sexual fish. Nature 344:864-866.

36. LYLES, A.M.; DOBSON, A.P. 1993. Infectious disease and intensive management: population dynamics, threatened hosts, and their parasites. J. Zoo and Wildlife Med. 24(3):315-326.

37. LYTHGOE, K.A. 2000. The coevolution of parasites with host-acquired immunity and the evolution of sex. Evolution. 54(4):1142-1156.

38. MARTENS, K.; SCHÖN, I. 2000. Parasites, predators and the Red Queen. Trends in Ecology \& Evolution. 15: 392-393.

39. MICHAELI, D.; SENYK, G.; MAOZ, A.; FUCHS, S. 1972. Ascaris cuticle collagen and mammalian collagens: cell mediated and humoral immunity relationships. J. Immunol. 109:103-109.
40. MOCK, B.A.; GILL, D.E. 1984. The infrapopulation dynamics of trypanosomes in red- spotted newts. Parasitol. 88:267-282.

41. O'BRIEN, S.J.; EVERMANN, J.F. 1988. Interactive influence of infectious disease and genetic diversity in natural populations. Trends in Ecol. and Evol. 3(10):254-259.

42. OWENS, I. 2002. Male-only care and classical polyandry in birds: phylogeny, ecology and sex differences in remating opportunities. Phil. Trans. R. Soc. Lond. 357:283-293.

43. PALMER, A.R. 1994. Fluctuating asymmetry analyses: a primer. En: Markow, T.A. ed. Developmental instability: its origins and evolutionary implications. Kluwer Publishers. (Dutrecht, Holanda). p.335-364.

44. PITHER, J.; TAYLOR, P.D. 2000. Directional and fluctuating asymmetry in the black-wing damselfly Calopteryx maculata (Beauvois) (Odonata: Calpterygidae). Can. J. Zool. 78:1740-1748.

45. POLAK, M. 1997. Ectoparasitism in mother causes higher positional fluctuating asymmetry in their sons: implications for sexual selection. Am. Nat. 149: 955974.

46. PROCTOR, H.; OWENS, I. 2000. Mites and birds: diversity, parasitism and coevolutiom. Trends in Ecology and Evolution. 15(9):358-364.

47. RHODE, K. 1990. Phylogeny of platyhelminthes, with special reference to parasitic groups. Internal. J. Parasitol. 20:979-1007.

48. RICO-HERNÁNDEZ, G. 2004. Implicaciones de enfermedades infecciosas en la conservación de fauna silvestre de vida libre. Rev. U.D.C.A Act. E Div. Cient. 7(1):59-67.

49. RICO-HERNÁNDEZ, G.; JUAN-SALLÉS, C.; GARNER, M.M.; BARR, B.C. 2004. Pulmonary besnoitiasis in patagonian hare (Dolichotis patagonum) associated with interstitial pneumonia. Vet. Pathol. 41:408-411.

50. SANTOS-ANGONESI, P.; ALMEIDA-SILVA, B.; LUCENAMENDES, S.; DOS SANTOS PYRRHO, A. 2009. Endoparasitos em Muriquis-Do-Norte, Brachyteles hypoxanthus, Isolados em Pequeno Fragmento de Mata Atlantica. Neotropical Primates 16(1): 15-17. 
51. SCARPASSA, V.M.; TADEI, W.P.; KERR, W. 1992. Biology of amazonian anopheline mosquitoes. XVI. Evidence of multiple insemination (Poliandry) in Anopheles nuneztovari Gabaldoni, 1940 (Diptera:Culicidae). Rev. Brasil. Genet. 15(1):51-64.

52. SCOTT, M.E. 1988. The impact of infection and disease on animal populations: Implications for conservation biology. Conservation Biology. 2:40-56.

53. SHERMAN, P.W.; SEELEY, T.D.; REEVE, H.K. 1988. Parasites, pathogens and polyandry in social Hymenoptera. American Nat. 131:602-610.

54. SHYKOFF, J.A.; BUCHELI, E.; KALTZ, O. 1996. Flower lifespan and disease risk. Nature. 379: 799.

55. STONER, K.E.; GONZÁLEZ-DI PIERRO, A.M.; MALDONADO-LÓPEZ, S. 2005. Infecciones de parásitos intestinales de primates: Implicaciones para la conservación. Universidad y Ciencia. Número Especial II: 61-72.

56. STUART, M.D.; STRIER, K.B. 1995. Primates and parasites: a case for a multidisciplinary approach. Internal J. Primatol. 16(4):577-593.

57. THOMPSON, J.N. 1987. Symbiont-induced speciation. Biol. J. Linnean Soc. 32:385-393.
58. THOMPSON, J.N. 1994. The coevolutionary process. University of Chicago Press. (Chicago, USA). 376p.

59. THORNHILL, R. 1992. Fluctuating assymmetry and the mating system of the Japanese scorpionfly. Animal Behavior. 43:867-879.

60. VALDESPINO, C.; RICO-HERNÁNDEZ, G.; MANDUJANO, S. 2010. Gastrointestinal parasites of howler monkeys (Alouatta palliata) inhabiting the fragmented landscape of the Santa Marta mountain range, Veracruz, Mexico. Am. J. Primatol. 71:1-10.

61. WEST, S.A.; LIVELY, C.M.; READ, A.F. 1999. A pluralist approach to sex and recombination. J. Evol. Biol. 12:1003-1012.

62. YAN, G.; SEVERSON, D.W.; CHRISTENSEN, B.M. 1997. Costs and benefits of mosquito refractoriness to malaria parasites: implications for genetic variability of mosquitoes and genetic control of malaria. Evolution 51:441-450.

Recibido: Marzo 24 de 2010

Aceptado: Junio 9 de 2011 